\title{
Ocupação do espaço urbano: observações históricas e a expansão da Península da Ponta D'areia em São Luís (MA) entre os anos de 2004 e 2016
}

Este trabalho objetiva fazer reflexões sobre a evolução da ocupação do solo na Península da Ponta D'areia, na ilha de São Luís do Maranhão entre os anos de 2004 e 2016. Inicialmente esta área abrigava colônias de pescadores, que transportavam em suas embarcações pessoas do centro da cidade para as praias e que, após a construção da Ponte José Sarney (1970) iniciou o processo de urbanização e modificações da paisagem natural através da remoção de dunas e vegetação. As análises deste trabalho iniciaram-se no ano de 2004, momento em que a Península começou a receber grandes investimentos do setor imobiliário através da construção de grandes condomínios residenciais de alto padrão, transformando a paisagem local. Para o início das análises buscou-se por informações históricas da região da Península da Ponta D’areia em São Luís. Foram selecionadas as imagens da região pelo software Google Earth Pró nos anos de 2004, 2010 e 2016 que foram georreferenciadas, rasterizadas e vetorizadas através da criação de polígonos manualmente, delimitando e quantificando áreas de vegetação, solo exposto e área urbanizada. Estes dados vetoriais gerados no mapeamento foram analisados e classificados em ambiente SIG, fazendo a evolução da ocupação por imagem dos anos analisados, possibilitando a reflexão sobre como a atuação de grandes investimentos conseguiu transformar em uma década uma região nobre da cidade de São Luís.

Palavras-chave: Análises Ambientais; Ocupação Urbana; Geoprocessamento; Modificações Ambientais.

\section{Urban space occupation: historical observations and the expansion of the Península da Ponta D’areia in São Luís (MA) between the years 2004 and 2016}

\footnotetext{
This work objective to make reflections (on / about) the evolution of soil occupation in the Peninsula Ponta D'areia region, on the São Luís island of Maranhão between the years 2004 and 2016. Initially this area was occupied by colonies of fishermen, who transported people from the center of the city to the beaches, and after the construction of José Sarney bridge (1970), began the process of urbanization and modifications of the natural landscape through the removal of dunes and vegetation. The analysis of this work began in the year 2004, when the Peninsula began to receive large investments in the real estate sector through the construction of large residential condominiums of high standard, transforming the local landscape. For the beginning of the analyzes, historical information was obtained from the Península da Ponta D'areia region in São Luís. The images of the region were selected by Google Earth Pro software for the years 2004,2010 and 2016, which were georeferenced, rasterized and vectorized by creating polygons manually, delimiting and quantifying areas of vegetation, exposed soil and urbanized area. These vector data generated in the mapping were analyzed and classified in a GIS environment, making the evolution of the occupation by image of the analyzed years, allowing the reflection on how the performance of large investments (succeeded) transformed in a decade a noble region of the city of São Luís.
}

Keywords: Environmental Analysis; Urban Occupation; Geoprocessing; Environmental Modifications.

\section{Topic: História Ambiental}

Reviewed anonymously in the process of blind peer.

Glauber Tulio Fonseca Coelho

Universidade Anhanguera, Brasil

http://lattes.cnpq.br/6219166502160869

tuliosux@gmail.com

Layse Lorena Neves Sales

Faculdade Pitágoras de São Luís, Brasil

http://lattes.cnpq.br/5078801917465786

lorenasales.eng@gmail.com

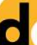

DOI: 10.6008/SPC2595-430X.2017.001.0002
Received: 05/07/2017

Approved: 08/09/2017

\section{Referencing this:}

COELHO, G. T. F.; SALES, L. L. N.. Ocupação do espaço urbano: observações históricas e a expansão da Península da Ponta D'areia em São Luís (MA) entre os anos de 2004 e 2016. Social Evolution, v.1, n.1, p.16-26, 2017. DOI: http://doi.org/10.6008/SPC2595430X.2017.001.0002 


\section{INTRODUÇÃO}

Historicamente, os $7.408 \mathrm{~km}$ do litoral brasileiro foram povoados de acordo com um padrão descontínuo, onde se identificam zonas de adensamento, preferencialmente em torno de estuários. No Nordeste do país, as áreas onde ocorre ocupação urbana (residências, calçadões, casas de veraneio, quiosques e outras edificações), são aquelas onde existe maior valorização econômica do trecho devido a uma série de fatores naturais e sociais os quais atraíram muitas pessoas (ARAUJO et al, 2007).

A capital do estado do Maranhão, São Luís, é hoje uma grande aglomeração urbana situada ao litoral norte de seu estado, a $2^{\circ}$ ao Sul do Equador, estando a 24 metros acima do nível do mar. A intensificação de sua ocupação espacial e crescimento demográfico a partir da segunda metade do século XX refletem diretamente na apropriação do espaço urbano pela população, atingindo, de acordo com o censo de 2010 realizado pelo IBGE a população de 1.014.837 habitantes, sendo a principal cidade da Região Metropolitana da Grande São Luís, que ainda inclui os municípios de São José de Ribamar, Raposa e Paço do Lumiar. São Luís é a única cidade brasileira fundada pelos franceses, sendo uma das três capitais brasileiras localizadas em ilhas (as outras são Florianópolis e Vitória).

Uma das características notáveis da expansão urbana e crescimento demográfico é a intensificação da utilização do solo urbano como mercadoria e meio de acumulação capitalista, favorecendo aos poucos que possuem grande parte de terrenos disponíveis e empresas incorporadoras de imóveis. Favorecidos por diversos instrumentos, como a especulação imobiliária e estratégias de marketing, os detentores do capital conseguem valorizar áreas e vender sonhos de moradia ou trabalho, ditando a forma como o espaço deve ser ocupado.

É notável que uma das áreas da capital maranhense que sofreu transformações importantes na ocupação de seu solo, verticalização de moradias (diga-se, construção de prédios), presença de estabelecimentos comerciais, turismo e lazer é a hoje chamada Península da Ponta D’Areia.

Segundo Santos (2013), a região da Ponta D'areia, nas décadas de 1950 e 1960, era formada por colônias de pescadores que utilizavam suas embarcações para o transporte de pessoas que pretendiam se deslocar do centro da cidade para a praia. Possuía uma exuberante vegetação (arbórea e arbustiva) e dunas recobertas por vegetação típica de áreas costeiras.

Com a construção da ponte que ligou o centro às praias, inicia-se o processo de modificações da paisagem natural, através da remoção de dunas e desmatamento, visando à abertura de estradas e o loteamento da área (PAIVA, 2007).

A partir do ano de 2004, a Península da Ponta D’areia começa a receber investimentos maiores do setor imobiliário, essencialmente na construção de novos condomínios residenciais de alto padrão. No final do ano de 2014, é inaugurado o espigão costeiro na região da Península da Ponta D’Areia, obra com viés ambiental, paisagístico e de lazer, consolidando um novo ponto turístico e cartão postal da cidade de São Luís. A área em estudo está situada na região da Ponta D’Areia, na cidade de São Luís, conforme figura 1. 


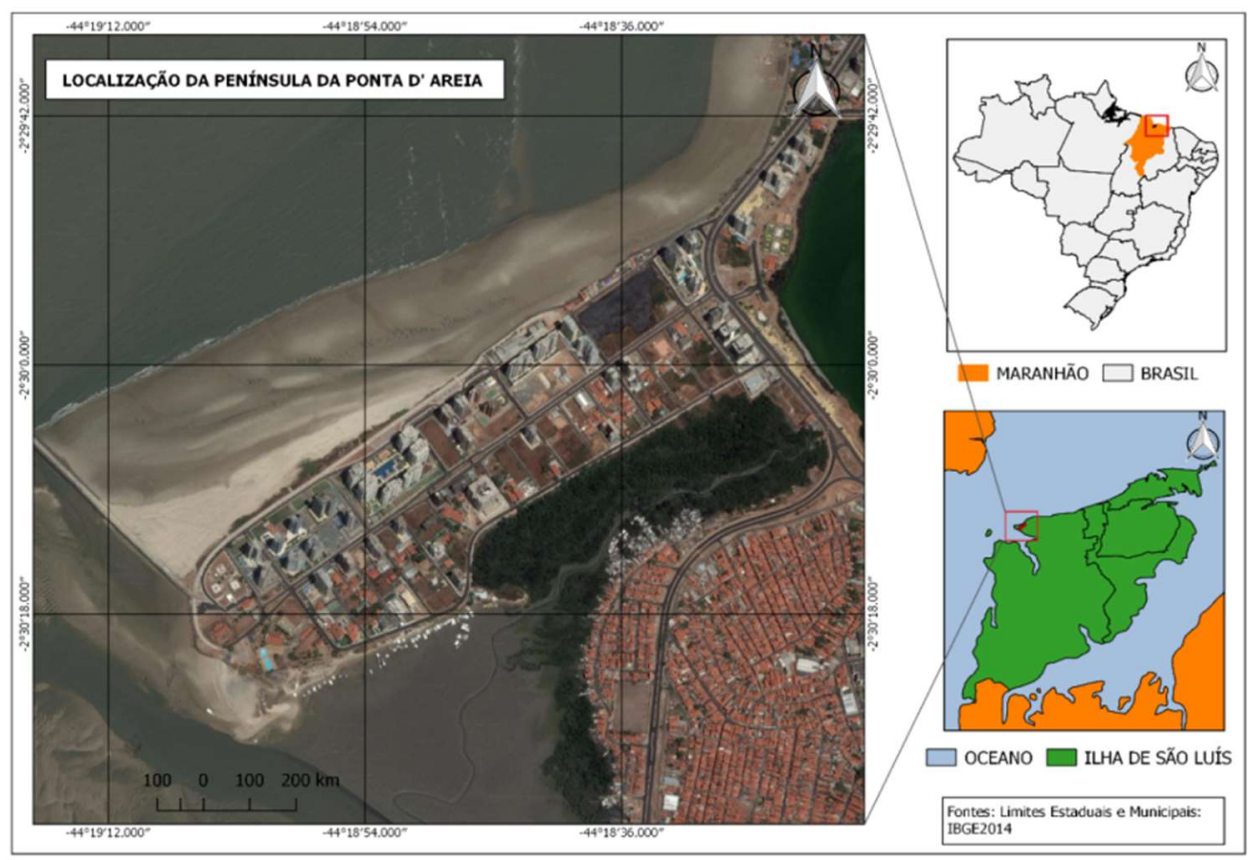

Figura 1: Localização da Península da Ponta D’areia.

A região da Ponta D'areia pouco tem sua história oficializada em arquivos e livros. Sabe-se que anteriormente a década de 1970, a região era ocupada por colônias de pescadores que, além das atividades de pescaria, faziam o transporte de pessoas do centro da cidade para a região de praia. Não havia urbanização qualquer no local. A região era conhecida também por abrigar o Forte de Santo Antônio da Barra de São Luís, fortificação antiga que permaneceu abandonada por muitos anos devido a constante necessidade de reparos decorridos da destruição causada pela força do mar.

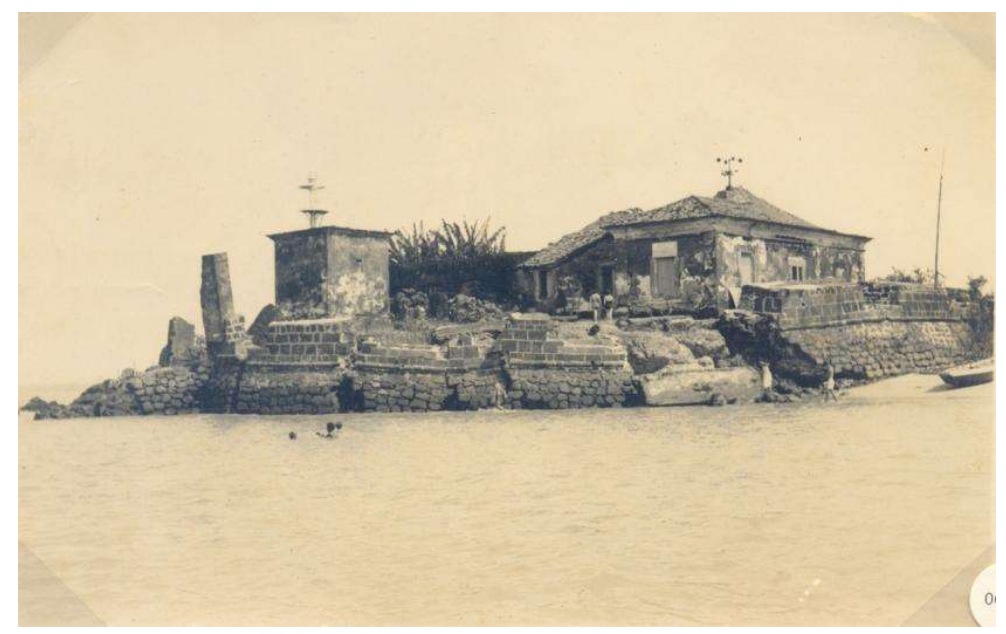

Figura 2: Forte de Santo Antônio da Barra de São Luís, sem datação.

Foi no governo de José Sarney (1966-1970) que a ponte com próprio nome do governador seria inaugurada. Na capital, tiveram maior repercussão, além do asfaltamento das artérias do centro urbano, a construção da ponte sobre o Rio Anil, permitindo o surgimento de modernos bairros na orla praiana, e a barragem do rio Bacanga, possibilitando fácil acesso ao porto do Itaqui, cuja construção foi iniciada, conforme promessa antes feita pelo presidente Jânio Quadros (MEIRELES, 2001). 
A figura 3 mostra uma imagem aérea da cidade de São Luís, na década de 30. A parte urbanizada se refere ao centro da cidade e destaca-se a ausência da ponte José Sarney e terras ainda não ocupadas do outro lado da Baía. O círculo em vermelho indica a região onde seria construída a ponte José Sarney.

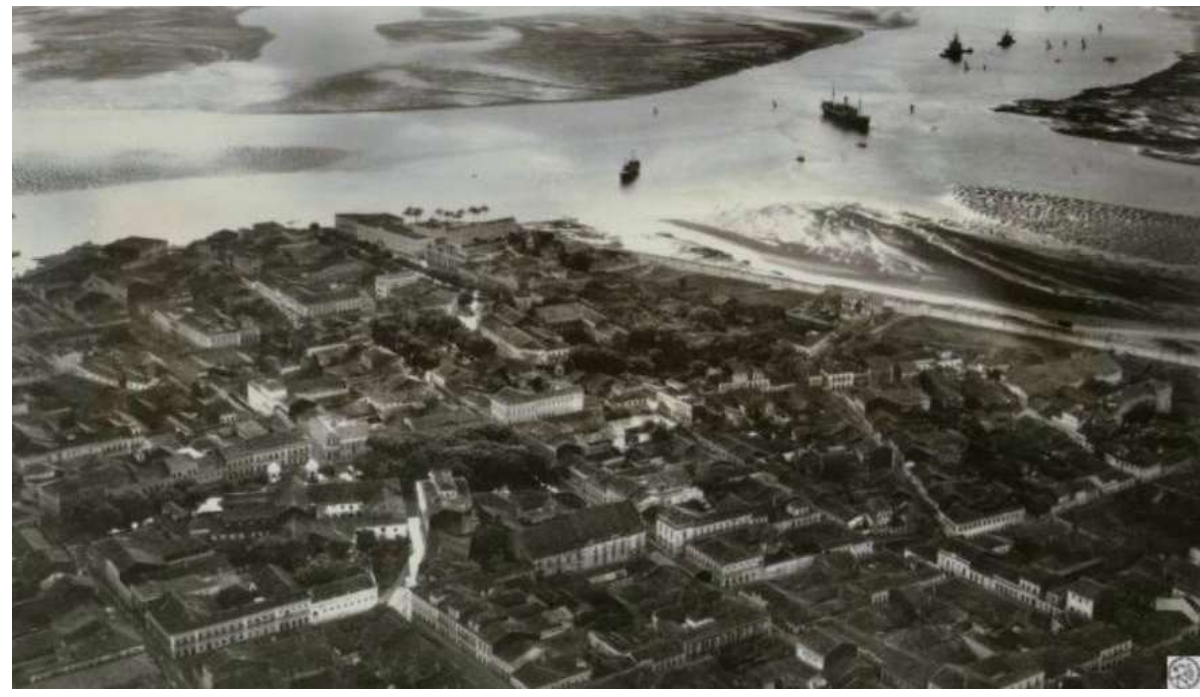

Figura 3: Vista aérea da cidade de São Luís na década de 30.

Autores como Ribeiro Júnior (1999), relatam um pouco das novas regiões da cidade que começam a se configurar na década de 70:

São marcos desse fenômeno re-espacializante a construção da Ponte José Sarney, inaugurada em 1970, que encurtaria o caminho da cidade para as praias, enobrecendo uma vasta área do seu território, e a edificação da barragem do rio Bacanga, também concluída no ano de 1970. Abriram-se, assim, duas frentes ocupacionais:

I.uma, ao Norte, em direção do litoral balneário, futura área nobre da cidade (São Francisco, Renascença, Calhau, Ponta D’areia, São Marcos,Olho D'água), onde os negócios imobiliários ganhavam vultuosidade, setor da economia urbana que adquire notável dimensão então;

II.outra, a Sudoeste, região de fraca densidade demográfica, mas que logo se tornaria tradicional zona de ocupação periférica da cidade (Anjo da Guarda, Vila Nova, Fumacê, Vila Embratel, Sá Viana, Vila Maranhão), abrigando parcela crescente da população pobre e, que facilitaria o acesso entre o Porto de Itaqui, o qual, em 1971, seria oficialmente inaugurado e a zona central da cidade, através de uma rodovia de pouco mais de $9 \mathrm{Km}$.

Corroborando com a citação anterior, SANTOS (2013) afirma que a expansão da cidade para diferentes áreas do espaço do município transformou cada vez o solo urbano em mercadoria. Com o advento da Ponte José Sarney, construída no início da década de 70 por sobre o rio anil, ligando a velha cidade a novas áreas, houve uma ruptura com o traçado urbano e o modo de vida tradicional do ludovicense, provocando, por conseguinte, a saída das famílias de classe média e alta (grupos dominantes) do antigo núcleo central em direção ao que se convencionou chamar de Cidade Nova (localizada mais ao norte da cidade e na orla marítima). Com o novo acesso a orla da cidade, por terra, as praias da região da Ponta D'areia passam a ser mais movimentadas, como mostra a figura 4, obtida nos arquivos do Jornal "O Imparcial".

A busca por imagens da região da Ponta D'areia resultou em alguns frutos, mas poucos relacionados especificamente a região da Península. A figura 5 faz parte do acervo do MAVAM e foi extraída de um vídeo com tomadas históricas da cidade de São Luís, mostrando uma tomada aérea da região da Península na década de 70, porém sem datação exata. 


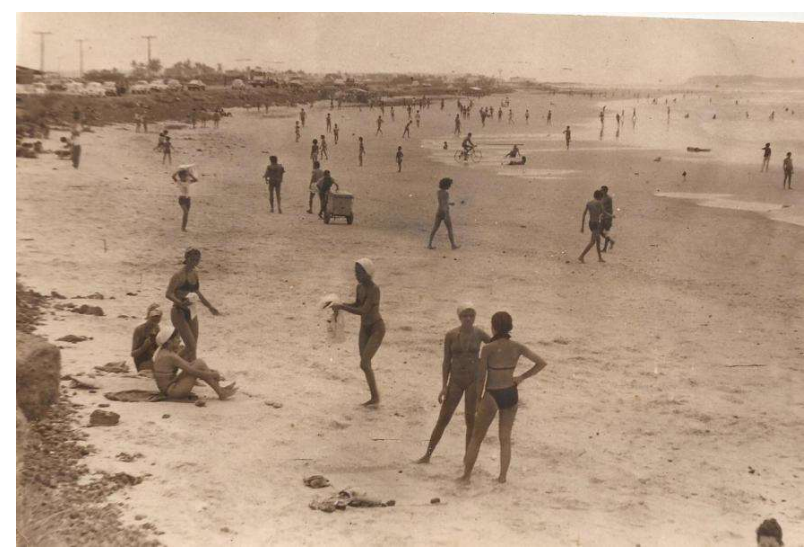

Figura 4: Praia da Ponta D’areia em 1976.

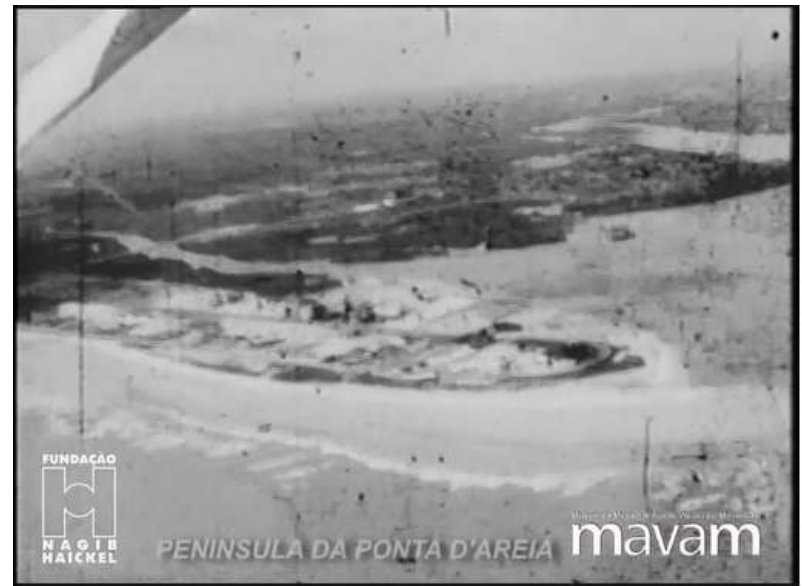

Figura 5: Península da Ponta D’areia na década de 1970.

É possível observar que existe arruamento, porém muitas áreas ainda eram ocupadas por areia e vegetação esparsa. Este início de urbanização foi impulsionado durante a gestão do então prefeito Haroldo Tavares (1971-1975), engenheiro civil que antes de assumir a prefeitura era secretário de Viação e Obras Públicas no governo de José Sarney.

Dentre suas medidas mais importantes, Haroldo Tavares criou em 1971 uma imobiliária municipal chamada SURCAP (Sociedade de Melhoramentos e Urbanismo da Capital) que recebeu da União as glebas que viriam a guiar a expansão da capital maranhense, dentre elas na região da Ponta D'areia. Parte destas glebas foram desmembradas em lotes residenciais e parcelas para empreendimentos turísticos, dentre eles, presentes na Península está o late Clube de São Luís, inaugurado em 1974. É atribuído também a Haroldo Tavares o aterro de parte da Península, facilitando sua urbanização.

Por muitos anos a região da Península teve desenvolvimento e ocupação humana lenta, sendo uma região pouquíssimo habitada. Dentre outras razões, em diálogos com habitantes locais mais antigos, estavam a precariedade de infraestrutura urbana principalmente no tocante ao fornecimento de água potável, ao asfaltamento e iluminação pública. Os poucos moradores da região ou eram os considerados "aventureiros" por ali fixar residência ou era os que possuíam residências de veraneio.

Este trabalho tem como objetivo principal observar e fazer reflexões acerca da evolução da ocupação do solo na região da Península da Ponta D’areia em São Luís entre os anos de 2004 e 2016. Para atingir tal objetivo, o trabalho primeiro buscou expor informações históricas da região da Ponta D’areia. Além disso foi feita a análise de imagens geoprocessadas dos anos de 2004, 2010 e 2016, delimitando e quantificando classes como vegetação, solo exposto e área urbanizada e fazendo a evolução da ocupação por imagem através destes anos.

\section{METODOLOGIA}

Para entender um pouco da história de formação e ocupação do espaço da região da Península da Ponta D'Areia, foi necessário buscar em publicações históricas, artigos, teses e dissertações diversas, principalmente nas áreas de história, geografia e economia. Foram realizadas buscas em arquivos históricos nos dois principais jornais periódicos do estado do Maranhão, sendo eles "O Imparcial" e "O Estado do 
Maranhão", e no MAVAM (Museu da Memória Áudio Visual do Maranhão) no intuito de encontrar publicações e fotos históricas da região do objeto de estudo. Foi realizada também entrevista com moradores antigos da região.

Em relação a realização da análise do uso e ocupação do solo da região estudada nos anos pretendidos através de imagens geoprocessadas, a definição dos anos de análise se baseou, além da qualidade de imagens disponíveis, no início da aceleração do desenvolvimento imobiliário da região, ano este de 2004. As imagens de satélite foram obtidas através do software Google Earth Pró e salvas na escala de 1:15.000 para os anos de 2004, 2010 e 2016.

\section{Georreferenciamento e Rasterização}

O tratamento das imagens a serem analisadas foram feitos no software QGis 2.14, iniciando pelo georreferenciamento, que é o processo de obtenção de coordenadas de pontos nas imagens, esse método é denominado pontos de controle, ou modelo polinomial, que consiste em uma função polinomial cujos parâmetros são determinados a partir das coordenadas de pontos homólogos, que correspondem aos conjuntos de feições da base de dados $(x, y)$. Cruzamento de ruas, construções, encontro de rios são opções naturais de pontos de controle. Segundo Richards (1993), deve-se escolher no mínimo de 6 a 10 pontos de controle, de forma que fiquem bem espalhados na imagem.

Para o georreferenciamento individual das imagens da Península da Ponta D’areia foram utilizados como pontos de controle os cruzamentos de ruas e avenidas como os da Rua Tupinambás, Avenida Nina Rodrigues, Rua São Marcos, e construções como as do late Clube de São Luís, o Hotel Praia Mar e o Forte de Santo Antônio.

\section{Análise das imagens e Vetorização Manual}

Após georreferenciadas, utilizando ainda o software Quantum Gis versão 2.14 com base em análises das características de ocupação do solo na área da Península, as imagens dos anos analisados foram mapeadas e classificadas através de um SIG (Sistema de Informações Geográficas). As classificações foram vetorizadas manualmente, delimitando áreas de interesse como arruamento, vegetação, solo exposto e área urbanizada, como são descritas abaixo:

Área de vegetação mista: A vegetação mista é caracterizada pela distribuição equilibrada entre vegetação gramínea e arbórea, campo cerrado, um campo com elementos arbóreo-arbustivos esparsos, campo sujo e campo limpo.

Área urbanizada: As áreas urbanas representam os espaços ou áreas que possuem urbanização verdadeiramente efetivada. Estas áreas são identificadas basicamente pela presença de áreas residenciais, sejam elas oriundas de meios legais ou de processos de invasão territorial. Entram também na quantificação, áreas referentes ao setor terciário, representado pelos estabelecimentos comerciais e de serviços, incluindo áreas de lazer, áreas arborizadas e até mesmo estacionamento. Por último, estão inclusas as áreas 
correspondentes ao setor industrial. Vale ressaltar que, as áreas aqui informadas serão dadas em metros quadrados $\left(\mathrm{m}^{2}\right)$.

Área de ruas - ruas, avenidas e acessos que caracterizem área de pavimentação. Para efeito de quantidade de áreas, esta classificação foi contabilizada dentro da área urbanizada.

Área de solo exposto - As áreas de solo exposto são as áreas que não possuem cobertura vegetal, que foi removida para a utilização do solo com outro propósito, como a construção de algum empreendimento.

Após a delimitação das áreas de interesse para os anos de estudo, foram confeccionados mapas para demonstrar de forma visual a evolução da ocupação do solo urbano na região estudada, além de serem geradas tabelas com as áreas de cada uma das categorias. Por fim, fez-se uma comparação da modificação da ocupação da região nos anos estudados.

\section{RESULTADOS E DISCUSSÕES}

A partir do ano de 2004 é verificada uma franca expansão da urbanização da Península da Ponta D'areia, através da construção de condomínios de alto padrão e obras de urbanização. Através da análise de imagens de satélite, é possível verificar como a área, em 2004 ainda tinha grande parte constituinte de vegetação mista (Figura 6). No mapa com as delimitações das áreas de interesse, é exposto de forma mais clara como era a ocupação da região no ano de 2004. A quantificação das áreas resultou na Tabela 1.

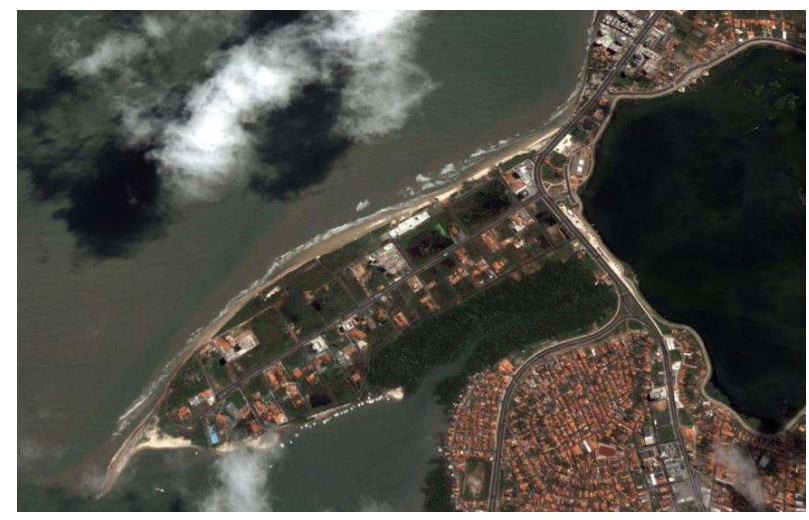

Figura 6: Imagem aérea da Península da Ponta D’areia em 2004.

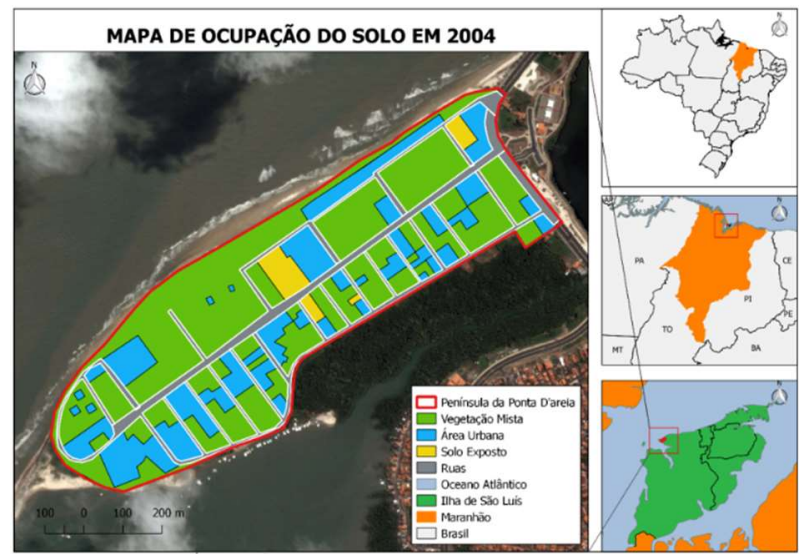

Figura 7: Mapa de ocupação da Península da Ponta D’Areia em 2004.

Tabela 1: Área por classe (2004).

\begin{tabular}{|c|c|c|}
\hline Área por Classe (2004) & $\mathbf{m}^{\mathbf{2}}$ & $\%$ do total \\
\hline Area de vegetação Mista & $285.421,00$ & $54,8 \%$ \\
\hline Área Urbanizada & $202.115,00$ & $38,8 \%$ \\
\hline Área de Solo Exposto & $32.892,00$ & $6,3 \%$ \\
\hline Area Total & $520.428,00$ & $100,0 \%$ \\
\hline
\end{tabular}

É de fácil observação que a maior parte do solo da região era de vegetação mista, mas já se observava expressiva área urbanizada. Entre 2004 e 2010 observou-se intensa ocupação da área, como é possível ver na imagem abaixo, datada de setembro de 2010. Seguindo a mesma lógica anterior, temos o mapa de 
ocupação para o ano de 2010 (Figura 9). Já para o ano de 2010, conforme tabela 02, é possível verificar expressivo aumento na área urbanizada da região.

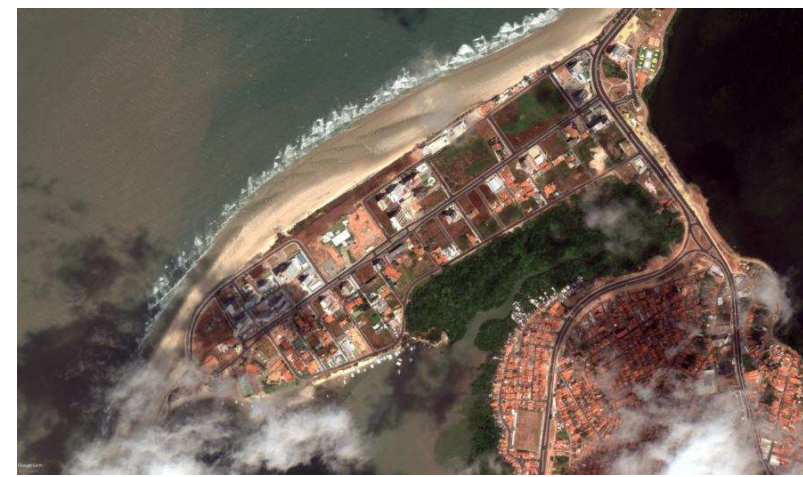

Figura 8: Imagem aérea da Península da Ponta D’areia em 2010.

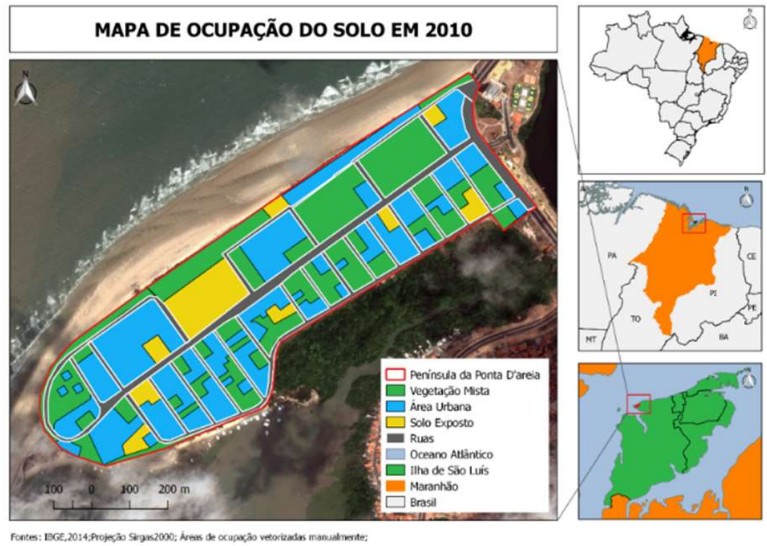

Figura 9: Mapa de ocupação do solo na Península da Areia em 2010.

Tabela 2: Área por classe (2010).

\begin{tabular}{|c|c|c|}
\hline Área por Classe (2010) & $\mathbf{m}^{\mathbf{2}}$ & $\%$ do total \\
\hline Area de vegetação Mista & $161.210,00$ & $32,6 \%$ \\
\hline Área Urbanizada & $307.571,00$ & $62,2 \%$ \\
\hline Área de Solo Exposto & $25.801,00$ & $5,2 \%$ \\
\hline Area Total & $494.582,00$ & $100,0 \%$ \\
\hline
\end{tabular}

Como consequência natural da urbanização, houve redução expressiva na área de vegetação mista. Já em 2016, como pode-se observar na figura 10, a urbanização da região está consolidada, com poucos espaços ainda a serem ocupados. Seguindo o mapa de ocupação da região no ano 2016, onde é possível observar o alto grau de urbanização da área.

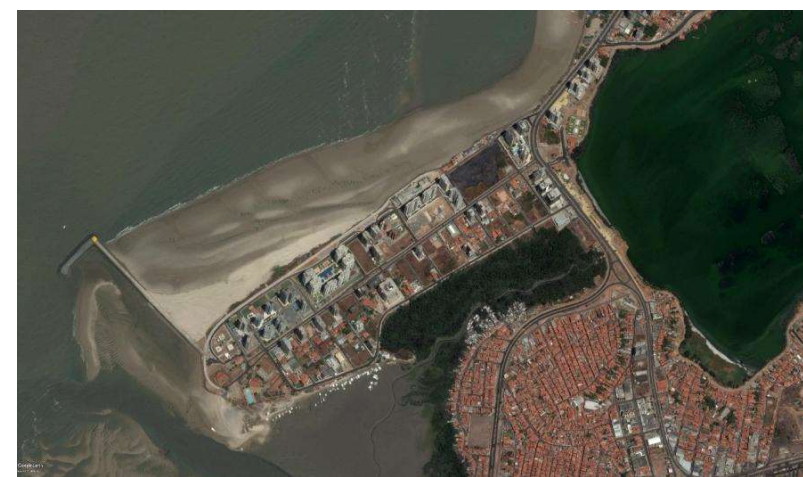

Figura 10: Imagem aérea da Península da Ponta D’areia em 2016.

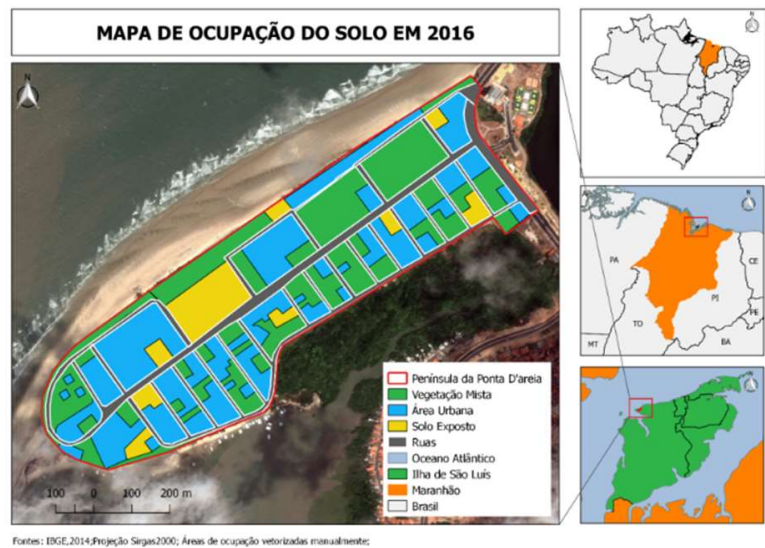

Figura 11: Mapa de ocupação do solo na Península da Ponta D’Areia em 2016.

Tabela 3: Área por classe (2016).

\begin{tabular}{|c|c|c|}
\hline Área por Classe (2016) & $\mathbf{m}^{\mathbf{2}}$ & $\%$ do total \\
\hline Area de vegetação Mista & $114.138,00$ & $22,9 \%$ \\
\hline Área Urbanizada & $366.005,00$ & $73,5 \%$ \\
\hline Área de Solo Exposto & $17.867,00$ & $3,6 \%$ \\
\hline Area Total & $498.010,00$ & $100,0 \%$ \\
\hline
\end{tabular}


Observa-se a continuação da expansão urbana da região, atingindo expressivos 73,5\% da área total, havendo redução da área de vegetação mista para próximo de $23 \%$. Na tabela 4 é possível observar a progressão da ocupação entre os três anos.

Tabela 4: Variação das áreas entre os anos estudados.

\begin{tabular}{|l|c|c|c|c|c|c|}
\hline \multirow{2}{*}{ Classes } & $\mathbf{2 0 0 4}$ & $\begin{array}{c}\text { Variação } \\
\mathbf{2 0 0 4 - 2 0 1 0}\end{array}$ & $\mathbf{2 0 1 0}$ & $\begin{array}{c}\text { Variação } \\
\mathbf{2 0 1 0 - 2 0 1 6}\end{array}$ & $\mathbf{2 0 1 6}$ & $\begin{array}{c}\text { Variação } \\
\mathbf{2 0 0 4 - 2 0 1 6}\end{array}$ \\
\cline { 2 - 7 } & $\mathrm{m}^{2}$ & $\%$ & $\mathrm{~m}^{2}$ & $\%$ & $\mathrm{~m}^{2}$ & $\%$ \\
\hline $\begin{array}{l}\text { Area de } \\
\text { vegetação } \\
\text { Mista }\end{array}$ & $285.421,00$ & $(-) 44 \%$ & $161.210,00$ & $(-) 29 \%$ & $114.138,00$ & $(-) 60 \%$ \\
\hline $\begin{array}{l}\text { Área } \\
\text { Urbanizada }\end{array}$ & $202.115,00$ & $(+) 52 \%$ & $307.571,00$ & $(+) 19 \%$ & $366.005,00$ & $(+) 81 \%$ \\
\hline $\begin{array}{l}\text { Área de } \\
\text { Solo } \\
\text { Exposto }\end{array}$ & $32.892,00$ & $(-) 22 \%$ & $25.801,00$ & $(-) 31 \%$ & $17.867,00$ & $(-) 46 \%$ \\
\hline
\end{tabular}

Houve, então uma forte expansão urbana na área, principalmente entre os anos de 2004 e 2010, fruto do surto imobiliário na região, acarretando um crescimento de 52\% na área urbanizada. Entre 2010 e 2016 percebe-se uma desaceleração da ocupação urbana, reduzindo este aumento para 19\%. Neste mesmo ritmo, a vegetação mista também diminui no período estudado. Na última coluna, percebe-se que entre 2004 e 2016 a área urbanizada da região cresceu 81\%, aumento expressivo em pouco mais de 10 anos. Outra informação interessante a ser observada é que a área total da Península teve redução significativa entre os anos de 2004 e 2010 e ligeiro aumento entre 2010 e 2016.

As diminuições das áreas entre os primeiros anos observados são decorrentes dos depósitos marinhos litorâneos, essencialmente porções de sedimentos quartzosos trazidos pelo mar. Já o aumento da área total entre 2010 e 2016 é provavelmente decorrente da obra do Espigão Costeiro, atenuando as forças da Maré.

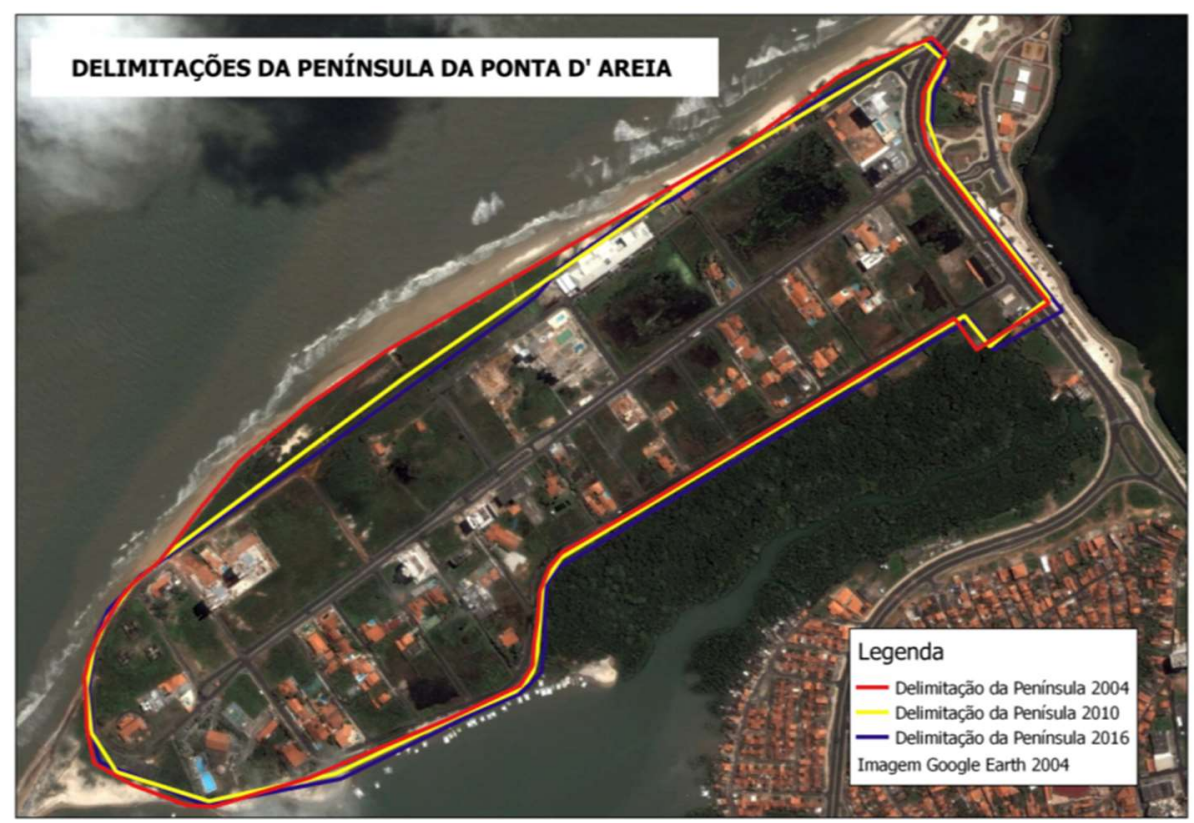

Figura 12: Diferença nas delimitações entre os anos estudados. 
É notória a aceleração do crescimento urbano da região após, 2004. A instalação de grandes construtoras como Franere, Mota Machado e Cyrela impulsionaram a construção de condomínios residenciais. Grandes detentoras de capital, conseguiram vender o sonho de moradia com vista privilegiada da praia, da baía ou do centro da cidade. $O$ investimento maciço do capital fez com que o valor do $\mathrm{m}^{2}$ dos imóveis residenciais tivessem aumento vertiginoso especialmente entre os anos de 2004 e 2010.

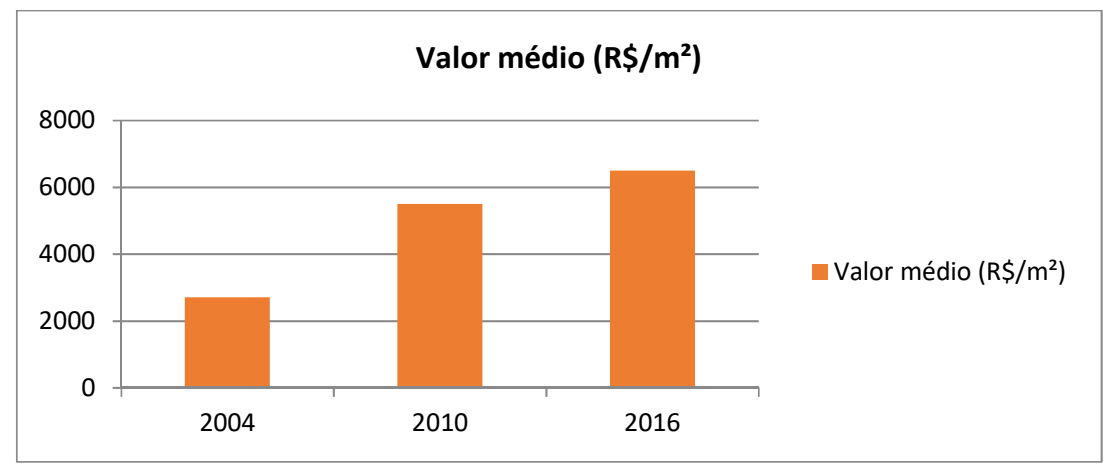

Gráfico 1: Valor médio do $\mathrm{m}^{2}$ entre 2004 e 2016.

\section{CONCLUSÃO}

É perceptível como no período entre 2004 e 2010 houve grande exploração do capital na área, praticamente duplicando o valor dos imóveis na região e aumentando em $52 \%$ a ocupação da área urbana da região. O crescimento entre 2010 e 2016 foi mais lento, especialmente pelos preços terem atingido níveis elevados e as condições econômicas do país terem progressivamente se deteriorado, dificultando a aquisição de novos imóveis e direcionando investimentos para outras áreas.

No término do mandato da governadora Roseana Sarney, em 2014, foi entregue a obra do espigão costeiro da Ponta D'areia, cuja concepção de projeto foi custeada pela empresa Vale e executado pelo governo do estado através da empresa Ducol Engenharia. A obra foi concebida, dentre outras razões, para conter o avanço da erosão do mar na região, bem como recompor a faixa de areia original do local em prazo de 10 anos. Além do espigão, foi feita a revitalização da área, urbanização direcionada ao turismo com a construção de passeios e quiosques de alimentação. Hoje, a área é considerada um dos pontos turísticos da cidade de São Luís, movimentando centenas de pessoas nos fins de semana, atraídas pelas belas paisagens, música, esportes, alimentação e artesanato.

É fácil observar como o investimento maciço na urbanização, tanto na esfera pública quanto na esfera privada tornaram a Península da Ponta D’areia hoje no local mais privilegiado e caro para se morar na cidade de São Luís. As transformações no local são notáveis, suas paisagens mudaram abruptamente em uma década. É óbvio que esgotado o potencial daquela área, os investimentos do capital haverão de estabelecer um novo bairro nobre para a cidade de São Luís.

Suspeita-se que a tendência será a verticalização de bairros na orla, ou próximos da orla de São Luís onde ainda prevalecem residências "horizontais". Alguns destes bairros ainda não receberam investimentos fortes neste sentido por haver restrições no plano diretor municipal sobre sua verticalização. O plano diretor 
da cidade de São Luís está em modificação, com o início das consultas públicas em 2015. A única dúvida que realmente paira é sobre a quem o novo plano diretor realmente irá beneficiar.

\section{REFERÊNCIAS}

ARAÚJO, M. C. B.; SOUZA, S. T.; CHAGAS, A. C. O.; BARBOSA, S. C. T.; COSTA, M. F.. Análise da Ocupação Urbana das Praias de Pernambuco, Brasil. Revista da Gestão Costeira Integrada, v.7, n.2, p.97-104, 2007.

BRITO, C. D. S. B.. O processo de uso e ocupação do solo urbano previsto no plano diretor de São Luís - MA. Dissertação (Mestrado em Geografia) - Universidade Federal de Rondônia, Porto Velho, 2009.

CEPSRM. Página Dinâmica para aprendizado do Sensoriamento Remoto. Centro Estadual de Pesquisas em Sensoriamento Remoto e Meteorologia, 2017.

MACHADO, G.; MACHADO, C. B. G.. Expansão Urbana na Península de Barra velha/SC e Problemas Ambientais Relacionados. In: CONGRESSO BRASILEIRO DE GEÓGRAFOS, 7. Anais. Vitória: UFES/AGB, 2014.
SILVA, Q. D.. Mapeamento geomorfológico da Ilha do Maranhão. Tese (Doutorado em Geografia) Universidade Estadual Paulista, Presidente Prudente, 2012.

MEIRELES, M. M.. História do Maranhão. 3 ed. São Paulo: Siciliano, 2001

PAIVA, E. K. G.. Evolução da forma urbana de São LuísMA: uma análise iconográfica. São Luís: 2007.

RIBEIRO JUNIOR, J. R. B.. Formação do Espaço Urbano de São Luís: 1612 - 1991. São Luís: FUNC, 1999.

SANTOS, L. E. N.. Estratégias do Capital na produção do espaço urbano de São Luís: sobre verticalização e desigualdades socioespaciais 2000-2010. Dissertação (Mestrado em Desenvolvimento Socioeconômico) Universidade Federal do Maranhão, São Luís, 2013. 